Review

\title{
Newborn screening of neuromuscular diseases
}

\author{
Tamara Dangouloff ${ }^{\mathrm{a}}$, François Boemer ${ }^{\mathrm{b}}$, Laurent Servais ${ }^{\mathrm{a}, \mathrm{c}, *}$ \\ ${ }^{a}$ Division of Child Neurology, Reference Center for Neuromuscular Diseases, Department of Pediatrics, University Hospital Liège \& University of Liège, \\ Belgium \\ ${ }^{\mathrm{b}}$ Biochemical Genetics Lab, Department of Human Genetics, CHU of Liège, University of Liège, Liège, Belgium \\ ${ }^{\mathrm{c}}$ MDUK Neuromuscular Centre, Department of Paediatrics, University of Oxford, UK
}

Received 30 June 2021; received in revised form 7 July 2021; accepted 13 July 2021

Available online $\mathrm{xxx}$

\begin{abstract}
Neuromuscular diseases represent an heterogenous group of more than 400 diseases, with a very broad phenotypic spectrum. Given their rarity and complexity, neuromuscular diseases are often diagnosed with a very significant delay after which irreversible muscle damage may limit the efficacy of treatments when available. In this context, neonatal screening could constitute a solution for early detection and treatment. A systematic review of the literature in PubMed up to May 1, 2021, was conducted according to PRISMA guidelines, including classical neuromuscular diseases and diseases with a clear peripheral nervous system involvement (including central nervous system disease with severe neuropathy). We found seven diseases for which newborn screening data were reported: spinal muscular atrophy (9), Duchenne muscular dystrophy (9), Pompe disease (8), X-linked adrenoleukodystrophy (5), Krabbe disease (4), myotonic dystrophy type 1 (1), metachromatic leukodystrophy (1). The future of newborn screening for neuromuscular disorders pass through a global technological switch, from a biochemical to a genetic-based approach. The rapid development of therapy also requires the possibility to quickly adapt the list of treated conditions, to allow innovative therapies to achieve their best efficacy.
\end{abstract}

(C) 2021 Elsevier B.V. All rights reserved.

Keywords: Newborn screening; Neuromuscular disorder; Pompe disease; Spinal muscular atrophy; Duchenne muscular dystrophy.

This paper is an invited review for the special issue of Neuromuscular Disorders to celebrate Professor Victor Dubowitz's 90th birthday.

\section{Introduction and context}

Forty-five years ago, a stricto sensu mid-career 45year-old myologist proposed Creatine Kinase (CK) dosage as a valid approach for Duchenne muscular dystrophy (DMD) and introduced the concept of screening newborns for neuromuscular disorders [1]. At that time, phenylketonuria newborn screening (NBS) had only been recently implemented in most developed countries. This paper is a tribute to this former mid-career myologist who celebrates today his 90th birthday.

\footnotetext{
* Corresponding author at: CRMN Liège, CHR de la Citadelle, Boulevard du 12ème de Ligne, 4000 Liège, Belgium.

E-mail addresses: tamara.dangouloff@uliege.be (T. Dangouloff), laurent.servais@paediatrics.ox.ac.uk (L. Servais).
}

Forty-five years later, the Dubowitz disease (not to be confounded with Dubowitz syndrome...) [2], also inappropriately called 'spinal muscular atrophy type $2^{\prime}$ by a very limited number of physicians, has become the stereotype of the perfect indication for NBS in the neuromuscular field.

Neuromuscular diseases represent an heterogenous group of more than 400 diseases, with a very broad phenotypic spectrum. Until very recently, few disease-modifying treatments were available for most of them. However, with a growing understanding of pathophysiology and preclinical research, several transformative treatments have had dramatic effects on not only inflammatory diseases, but also genetic diseases such as congenital myasthenia (CMS), spinal muscular atrophy (SMA), Pompe disease, or Brown-VialettoVan Laere syndrome (BVVL). Promising preliminary data have also been reported in limb girdle muscular dystrophy, $\mathrm{X}$-linked myotubular myopathy or in DMD, for which five drugs have so far reached regulatory approval.

Given their rarity and complexity, neuromuscular diseases are often diagnosed after a very significant delay [3-6] during 
which irreversible muscle damage may limit the dramatic efficacy of early treatment administered patients $[7,8]$. Even in the absence of a muscle destruction process, such as in some form of CMS, the long diagnostic journey can cause decades of limitation in quality of life [9] before a correct diagnosis is established and the appropriate treatment is prescribed.

Neonatal screening is generally governed worldwide by the modified criteria proposed by Wilson and Jungner [10] which are widely used to determine whether screening for a disease should be included in an NBS panel. This list consists of the following ten items:

1 The condition sought should be an important health problem.

2 There should be an accepted treatment for patients with recognized disease.

3 Facilities for diagnosis and treatment should be available.

4 There should be a recognizable latent or early symptomatic stage.

5 There should be a suitable test or examination.

6 The test should be acceptable to the population.

7 The natural history of the condition, including development from latent to declared disease, should be adequately understood.

8 There should be an agreed policy on whom to treat as patients.

9 The cost of case-finding (including diagnosis and treatment of patients diagnosed) should be economically balanced in relation to possible expenditure on medical care as a whole.

10 Case-finding should be a continuing process and not a "once and for all" project.

These criteria are broadly applied across the world, with a much more conservative approach in European Union (EU) and UK in comparison with the US. As a consequence, the number of diseases screened in different countries, or even in different regions of a same country, varies significantly [11]. In line with these criteria, our mid-career myologist had already noticed in 1976 that "the stage does not yet seem set for a [UK] nationwide program of screening for preclinical Duchenne muscular dystrophy, but when the time is ripe for it the techniques will hopefully be sufficiently standardized for immediate application."[1]

NBS has been organized for the last 60 years as a metabolic and endocrine screening process, but many treatable genetic neuromuscular diseases in children, such as BVVL, CMS or SMA have no metabolic or endocrine marker, which causes additional challenges in implementation of screening.

Nevertheless, the dramatic difference observed between pre-symptomatic and post-symptomatic treated patients with SMA, the successful implementation of NBS for SMA across the world, and the pipeline of potential therapy, all suggest that several neuromuscular diseases could be targeted by NBS before our previous mid-career myologist celebrate his 100th birthday. In this context, we conducted a review of the existing pilot or official NBS programs in the area of neuromuscular disease.

\section{Methods}

\subsection{Literature search}

A literature search was conducted using Medline (PubMed) following the PRISMA checklist [12]. We searched for original, full-text articles reporting NBS program in neuromuscular disease published after the 70th birthday of Prof. Victor Dubowitz (i.e., August 06th 2001). To identify relevant articles, key terms related to NBS (e.g., 'neonatal screening', 'dried blood spot testing', 'dried blood', and 'guthrie') were combined with key terms for neuromuscular disease. The detailed search strategy is shown schematically in Supplementary file 1 . The literature search was conducted until May 1, 2021.

\subsection{Selection of studies}

Two researchers (TD, LS) first screened titles and abstracts independently for eligibility and then evaluated the full text. To be included, the articles had to be published original research, in English or French, and had to report NBS program for at least one neuromuscular disease, or a disease with a clear peripheral nervous system involvement (mostly peripheral neuropathy). The two reviewers compared their findings, and a list of studies for full-text screening was created. Reasons for article exclusion were recorded, and potential disagreements were specified to be resolved by consensus.

\subsection{Data extraction and presentation}

Studies were classified by disease screened: SMA, DMD, myotonic dystrophy type 1 (MD1), Pompe disease, $\mathrm{X}$-linked adrenoleukodystrophy (X-ALD), metachromatic leukodystrophy (MLD) and Krabbe disease.

Study characteristics related to publication (e.g., authors, year of publication, journal name) and study design (e.g., country, sample size...) were extracted.

\section{Results}

\subsection{Study selection process}

The initial searches identified 405 articles that describe NBS for neuromuscular diseases. After removing 108 duplicates, and screening by title and abstract, 84 articles were identified for full-text screening; 36 full-text studies were validated as eligible and 8 identified by bibliography were added. Supplementary file 2 shows the flowchart based on Preferred Reporting Items for Systematic Reviews and MetaAnalyses (PRISMA) guidelines used for the identification of these studies.

Articles concerning the same pilot project were disregarded and only the most recent update was considered. We retained studies demonstrating the efficacy of NBS on deidentified 
Guthries cards only if pilot projects with identified patients had not taken place.

\subsection{Spinal muscular atrophy}

SMA is a recessive disorder caused by a homozygous loss of function mutation (mostly a deletion of exon 7) of SMN1. There are three drugs approved for treatment [13] (nusinersen [14], onasemnogene abeparvovec [15] and risdiplam [16]), and three pre-symptomatic trials published or ongoing (Nurture: NCT02386553, SPR1NT: NCT03505099, Rainbowfish: NCT03779334). Several other drugs are in preclinical or early clinical development [17].

NBS for SMA has been reported in nine countries I subnational regions [18-25]. The first pilots were implemented in 2014 in Taiwan [18], and in New-York in 2016 [19]. Interestingly, these pilots were implemented prior to the approval of any medications, and some of the patients identified through these pilots could be included in pre-symptomatic studies [26]. The incidence found in these screening programs ranges from 1 in 5,000 in Italy to 1 in 28,000 in Ontario [27]. One of the lowest rates of incidence was found in New York [28], which may be explained by an increase in the use of preconception screening as a result of increased communication about the disease [29]. An additional reason of variability from study to study resides in the small number of cases in some reports, which over-weight the influence of a single case on the prevalence.

In most programs, the first tier of screening is done by quantitative real-time polymerase chain reaction (qPCR), while the second is done by MLPA. In the USA and Italy, qPCR is also used for the second tier.

Even if this remains to be confirmed in the next few years for SMA with later onset, no false negatives have yet been found in countries that have developed NBS programs. False positives were only encountered at the beginning of the pilot programs [27].

A recent survey has demonstrated that several countries anticipate to initiate a NBS program in the coming months and years, so that the number of newborn screened for SMA, today approximately $2 \%$ of the world population, should progressively climb to $24 \%$ of the total world population and $88 \%$ of the population of countries where a disease modifying treatment is available [27].

The characteristics of NBS programs in SMA are reported in Table 1.

\subsection{Pompe disease}

Pompe disease, also known as glycogenosis type 2, is an autosomal recessive inherited lysosomal storage disease caused by a deficiency of acid alpha-glucosidase.

Pompe disease has a wide clinical spectrum ranging from the infantile form, beginning in the first months of life, to adult forms. In the absence of treatment, the infantile form always leads to early death by cardiorespiratory failure or respiratory infection, usually before the age of one year.
Symptoms can appear at any age in the later forms and are related to progressive skeletal muscle dysfunction.

Enzyme replacement therapy (ERT) using alglucosidase alfa (Myozyme) was approved by the United States Food and Drug Administration (FDA) and European Medicines Agency (EMA) in 2006. Early treatment has been associated with better outcome [30,31].

The first NBS pilot was initiated in Taiwan in 2005 and has been regularly documented since then [31-35]. In the USA, since 2015, Pompe Disease is part of the Recommended Uniformed Screening Panel (RUSP) program and is implemented in almost half of the states [36-39]. Other projects were conducted in Mexico [40], Japan [41] and Brazil [42]. The rate of incidence reported across all screening program was extremely variable: 1 in 10,600 in Brazil, 1 in 20,000 in Mexico, Taiwan and in the US, and 1 in 38,000 in Japan.

The characteristics of NBS programs in Pompe disease are reported in Table 2.

\subsection{Duchenne muscular dystrophy}

DMD is the most common inherited muscular dystrophy in childhood and is characterized by progressive muscle weakness. It is caused by an out-of-frame mutation of the Dystrophin gene located on the $\mathrm{X}$ chromosome. The incidence is around 1 in 4,700 [43] of young males. The first symptoms most commonly appear at as early as two years of age; the disease manifests as a proximal weakness leading to a rapid loss of walking between the ages of seven and fifteen. The delay between the appearance of symptoms and diagnosis is on average two years [3]; this diagnostic errancy, which causes parental distress, can also create a delay in the child's care.

Five drugs have achieved US FDA approval: Deflazacort, a corticosteroid; and Eteplirsen, Casimersen and Golodirsen for exon skipping 51, 45 and 53, respectively. Vitolarsen has also been approved for exon 53 skipping. In the EU, only Ataluren has been conditionally approved [44]. The clinical efficacy of these different drugs remains modest.

We found nine pilot projects or official implementations for DMD [45-54] between 1974 and 2017. The aim of these screening programs, as there was no treatment approved when they were initiated, was most often to establish recommendations for the following-up of patients. An early follow-up seemed preferable, not only to avoid diagnostic delay, but also to prevent a recurrence in the family through genetic counselling.

The characteristics of NBS programs in DMD are reported in Table 3.

\subsection{Myotonic dystrophy 1}

MD1 is an autosomal dominant disorder characterized by muscle weakness, myotonia, early onset cataracts, and systemic manifestations (cerebral, endocrine, cardiac, gastrointestinal tract, uterus, skin, and immunologic involvement) that vary depending on the age of onset. 
Table 1

Newborn screening programs in SMA.

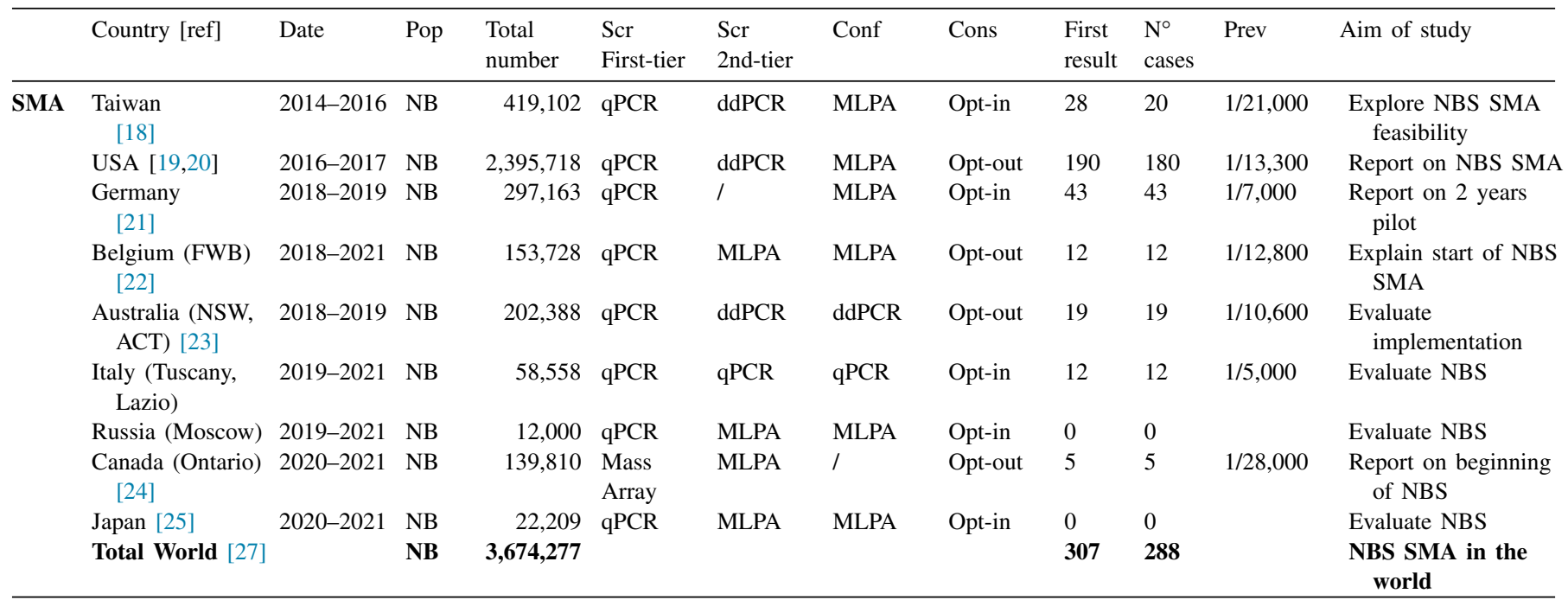

List of abbreviations: Conf: Confirmatory assay; Cons: parents' method of consent; ddPCR: digital droplet PCR; First result: Positive first result or inconclusive; FWB: Federation Wallonia-Brussels (Region of Belgium); MLPA: multiplex ligation-dependent probe amplification; NB: Newborn; ${ }^{\circ}$ cases: Number of confirmed cases; NSW/ACT: New South Wales and Australian Capital Territory (region of Australia); Pop: description of population screened; Prev: Prevalence; Ref: references used; Scr: Screening assay.

Table 2

Newborn screening programs in Pompe disease.

\begin{tabular}{|c|c|c|c|c|c|c|c|c|c|c|c|c|}
\hline & $\begin{array}{l}\text { Country } \\
{[\mathrm{ref}]}\end{array}$ & Date & Pop & $\begin{array}{l}\text { Total } \\
\text { number }\end{array}$ & $\begin{array}{l}\text { Scr } \\
\text { First-tier }\end{array}$ & $\begin{array}{l}\text { Scr } \\
\text { 2nd-tier }\end{array}$ & Conf & Cons & $\begin{array}{l}\text { First } \\
\text { result }\end{array}$ & $\begin{array}{l}\mathrm{N}^{\circ} \\
\text { cases }\end{array}$ & Prev & Aim of study \\
\hline \multirow[t]{6}{*}{$\begin{array}{l}\text { Pompe } \\
\text { disease }\end{array}$} & $\begin{array}{l}\text { Taiwan } \\
{[31,32]}\end{array}$ & 2005-2014 & NB & 669,797 & $\begin{array}{l}\text { Fluor } \\
\text { assay }\end{array}$ & I & $\begin{array}{l}\text { Leukocytes } \\
\text { Enzymatic assay }\end{array}$ & Opt-in & 4184 & $\begin{array}{l}13 \text { IOPD } \\
>19 \text { LOPD }\end{array}$ & $\begin{array}{l}\text { IOPD: } 1 / 51,500 \\
\text { LOPD: } 1 / 35,300 \\
\text { All: } 1 / 21,000\end{array}$ & $\begin{array}{l}\text { Demonstrate } \\
\text { advantage of early } \\
\text { treatment, even for } \\
\text { LOPD }\end{array}$ \\
\hline & $\begin{array}{l}\text { Mexico } \\
{[40]}\end{array}$ & $2012-2016$ & NB & 20,018 & $\begin{array}{l}\text { LC-MS- } \\
\text { MS }\end{array}$ & I & $\begin{array}{l}\text { Enzymatic }+ \\
\text { Molecular testing }\end{array}$ & Opt-in & 19 & 1 & $1 / 20,000$ & $\begin{array}{l}\text { Evaluate the results } \\
\text { of a lysosomal } \\
\text { NBS }\end{array}$ \\
\hline & $\begin{array}{l}\text { Japan } \\
{[41]}\end{array}$ & 2013-2016 & NB & 103,204 & $\begin{array}{l}\text { Fluor } \\
\text { assay }\end{array}$ & I & Molecular testing & Opt-in & 225 & $\begin{array}{l}0 \text { IOPD } \\
3 \text { LOPD }\end{array}$ & $\begin{array}{l}\text { LOPD: } 1 / 34,000 \\
\text { All: } 1 / 34,000\end{array}$ & $\begin{array}{l}\text { Summary of NBS } \\
\text { program + results }\end{array}$ \\
\hline & $\begin{array}{l}\text { USA } \\
(\mathrm{PA}) \\
{[38]}\end{array}$ & 2016-2019 & NB & 531,139 & $\begin{array}{l}\text { FIA-MS- } \\
\text { MS }\end{array}$ & I & $\begin{array}{l}\text { Enzymatic }+ \\
\text { Molecular testing }\end{array}$ & Opt-out & 115 & $\begin{array}{l}2 \text { IOPD } \\
31 \text { LOPD }\end{array}$ & $\begin{array}{l}\text { IOPD: } 1 / 265,500 \\
\text { LOPD: } 1 / 17,100 \\
\text { All: } 1 / 16,100\end{array}$ & $\begin{array}{l}\text { Evaluation of } \\
\text { benefits + challenges } \\
\text { of NBS }\end{array}$ \\
\hline & $\begin{array}{l}\text { USA } \\
\text { (CA) } \\
{[39]}\end{array}$ & 2018-2019 & NB & 453,152 & $\begin{array}{l}\text { FIA-MS- } \\
\text { MS }\end{array}$ & $\begin{array}{l}\text { Molecu- } \\
\text { lar } \\
\text { testing }\end{array}$ & - Molecular testing & Opt-out & 88 & $\begin{array}{l}2 \text { IOPD } \\
16 \text { LOPD }\end{array}$ & $\begin{array}{l}\text { IOPD: } 1 / 226,600 \\
\text { LOPD: } 1 / 28,300 \\
\text { All: } 1 / 25,200\end{array}$ & $\begin{array}{l}\text { Report on 1-year } \\
\text { NBS program }\end{array}$ \\
\hline & $\begin{array}{l}\text { Brazil } \\
{[42]}\end{array}$ & 2016 & NB & 10,567 & $\begin{array}{l}\text { Fluor } \\
\text { assays }\end{array}$ & & $\begin{array}{l}\text { Enzymatic }+ \\
\text { Molecular } \\
\text { testing + Urinary } \\
\text { GAGs analysis }\end{array}$ & Opt-out & 4 & 1 & $1 / 10,600$ & $\begin{array}{l}\text { Evaluation of } \\
\text { challenges of NBS }\end{array}$ \\
\hline
\end{tabular}

List of abbreviations: CA: California; Conf: Confirmatory assay; Cons: parents' method of consent; FIA-MS-MS: flow-injection mass spectrometry; First result: Positive first result or inconclusive; Fluor: Fluorometric; IL: Illinois; IOPD: infantile onset Pompe disease; LC-MS-MS: liquid-chromatography mass spectrometry; LOPD: late onset Pompe disease; MO: Missouri; NB: Newborn; $N^{\circ}$ cases: Number of confirmed cases; PA: Pennsylvania; Pop: description of population screened; Prev: Prevalence; Ref: references used; Scr: Screening assay. 
Table 3

Newborn screening programs in DMD and MD1.

\begin{tabular}{|c|c|c|c|c|c|c|c|c|c|c|c|c|}
\hline & $\begin{array}{l}\text { Country } \\
\text { [ref] }\end{array}$ & Date & Pop & $\begin{array}{l}\text { Total } \\
\text { number }\end{array}$ & $\begin{array}{l}\text { Scr } \\
\text { First-tier }\end{array}$ & $\begin{array}{l}\text { Scr } \\
\text { 2nd-tier }\end{array}$ & Conf & Cons & $\begin{array}{l}\text { First } \\
\text { result }\end{array}$ & $\begin{array}{l}\mathrm{N}^{\circ} \\
\text { cases }\end{array}$ & Prev & Aim of study \\
\hline \multirow[t]{6}{*}{ DMD } & $\begin{array}{l}\text { Germany } \\
{[51,54]}\end{array}$ & $1974-2011$ & NB $(M)$ & 537,000 & CK assay & l & & Opt-in & & 155 & $1 / 3,500$ & $\begin{array}{l}\text { Evaluation of opportunity } \\
\text { of NBS for DMD }\end{array}$ \\
\hline & $\begin{array}{l}\text { New Zealand } \\
{[52]}\end{array}$ & 1979 & NB (M) & 10,000 & CK assay & l & $\begin{array}{l}\text { Clinical } \\
\text { assessment }\end{array}$ & $?$ & & 2 & $1 / 5,000$ & Report on course of NBS \\
\hline & $\begin{array}{l}\text { USA } \\
(\mathrm{PA}) \\
{[49]}\end{array}$ & 1987-1995 & NB $(M)$ & 403,576 & CK assay & $\begin{array}{l}\text { CK } \\
\text { isozyme }\end{array}$ & $\begin{array}{l}\text { DMD } \\
\text { molecular } \\
\text { testing / } \\
\text { muscle } \\
\text { biopsy }\end{array}$ & $\begin{array}{l}\text { Opt-out, } \\
\text { verbal } \\
\text { consent }\end{array}$ & & 39 & $1 / 10,300$ & $\begin{array}{l}\text { Description of attitude of } \\
\text { patients + parents } \\
\text { diagnosed with or } \\
\text { without NBS toward } \\
\text { NBS }\end{array}$ \\
\hline & $\begin{array}{l}\text { Cyprus } \\
{[47]}\end{array}$ & 1992-1997 & NB $(M)$ & 30,014 & CK assay & l & $\begin{array}{l}\text { DMD } \\
\text { molecular } \\
\text { testing / } \\
\text { muscle } \\
\text { biopsy }\end{array}$ & Opt-out & 43 & 5 & $1 / 6,000$ & $\begin{array}{l}\text { Evaluation of the } \\
\text { method + implementation } \\
\text { of NBS pilot }\end{array}$ \\
\hline & $\begin{array}{l}\text { USA } \\
(\mathrm{OH}) \\
{[46]}\end{array}$ & 2007-2010 & NB (M) & 17,865 & CK assay & l & $\begin{array}{l}\text { DMD } \\
\text { molecular } \\
\text { testing }\end{array}$ & Opt-in & 168 & 3 & $1 / 6,000$ & $\begin{array}{l}\text { Evaluate of } \\
\text { method + feasibility of } \\
\text { NBS }\end{array}$ \\
\hline & $\begin{array}{l}\text { China } \\
\text { (Zhejiang) } \\
{[45]}\end{array}$ & 2017 & NB (M) & 18,424 & $\begin{array}{l}\text { CK-MM } \\
\text { assay }\end{array}$ & l & $\begin{array}{l}\text { DMD } \\
\text { molecular } \\
\text { testing }\end{array}$ & Opt-in & 13 & 4 & $1 / 4,600$ & $\begin{array}{l}\text { Recommendations for } \\
\text { follow-up care }\end{array}$ \\
\hline
\end{tabular}

List of abbreviations: CK-MM: Creatine kinase muscle; Conf: Confirmatory assay; Cons: parents' method of consent; DBS: DBS deidentified; First result: Positive first result or inconclusive; M: Male; Man: Manitoba; NB: Newborn; $\mathrm{N}^{\circ}$ cases: Number of confirmed cases; NY: New York state; OH: Ohio; PCR: polymerase chain reaction; PA: Pennsylvania; Pop: description of population screened; Prev: Prevalence; Ref: references used; Scr: Screening assay.

MD1 is caused by a pathological ( $>50)$ CTG repeat in the $D M P K$ gene. Anticipation, a phenomenon in which the age of onset of an autosomal dominant disease becomes earlier with each successive generation, typically occurs in maternal transmission of the disease. The most severe form is the congenital form ( $15 \%$ of cases) which includes severe generalized weakness at birth with respiratory distress, hypotonia and feeding difficulties. Patients subsequently develop delayed cognitive and motor milestones, intellectual disability, and autism spectrum disorder with the physical symptoms taking a potentially fatal course. The incidence is extremely variable from 0.5 to 1.8 per 100,000 [55].

Despite several pre-clinical developments [56], no specific disease-modifying therapy is currently available. Management consists primarily of monitoring for complications and standard of care (assistive devices, hormone therapy, pain medication).

We found one pilot project for MD1 in 2013, in the USA, using deidentified dried blood spot (DBS), with the aim of determining prevalence [57]. This was found to be 1 in 21,100 .

The characteristics of NBS program in MD1 are reported in Table 3.

\subsection{Krabbe disease}

Krabbe disease is an autosomal recessive lysosomal disease affecting the white matter of the central and peripheral nervous systems, characterized by neurodegeneration whose severity depends on the age of onset. Krabbe disease is caused by a loss of function mutation in both alleles of the GALC gene leading to a deficit in galactosylceramidase.

Historically, 85-90\% of patients were diagnosed with the infantile form, which is the most severe and manifests in the first six years of life. In those in whom the disease begins in the first year, a rapid neurological deterioration is observed, leading to death before the age of two years. Late-onset Krabbe disease is much more variable in its presentation and 
course [58]. The incidence of both forms of Krabbe disease is estimated to 1 in 100,000 [59].

The low incidence of the disease is an obstacle for the observation of the effectiveness of a pre-symptomatic treatment. Post-symptomatic treatment, presently limited to hematopoietic stem cell transplantation, slows disease progression. However, this is far from being transformative [60]. Pre-symptomatic treatment was initially presented as being much more efficient, but a recent report has demonstrated that only 1 of 18 patients treated before the onset of symptoms presented with mild disability; 13 of the other patients presented with severe disability, and four died [60-62].

We found four pilot projects for Krabbe disease as part of the introduction of NBS for a range of lysosomal diseases. The five-year NBS program in Mexico [40], with 20,000 newborn babies screened, found zero cases. The first US program in New York States screened more than two millions newborns and identified five case [63], the second, in Kentucky with 55,000 newborns, identified one case [64], and the third in Illinois, with almost 500,000 babies, identified eight cases: two infantile Krabbe disease and six probable late-onset Krabbe infants [65]. This NBS is a recommended disease in the RUSP but is now implemented in seven states in the USA. Recent publications have questioned the ethical basis of such screening [66].

The characteristics of NBS programs in Krabbe disease are reported in Table 4.

\subsection{X-linked adrenoleukodystrophy}

$\mathrm{X}$-ALD is a peroxisomal genetic disease caused by a loss of function mutation in $A B C D I$ gene. It is a devastating metabolic disorder affecting the adrenal glands, brain, and spinal cord. X-ALD affects hemizygous boys more severely than heterozygous girls $(60 \%)$. If untreated, X-ALD is most often fatal.

Corticosteroid treatment for adrenal insufficiency, hematopoietic stem cell transplantation, and gene therapy for neurologically devastating brain adrenoleukodystrophy administered at the very beginning of brain inflammation, have been associated with improved survival and functional outcomes [67].

The RUSP included X-ALD as a secondary condition in 2016. Only eight states in the US were conducting X-ALD NBS in 2019, rising to twenty in $2021[68,69]$. Several articles reported on the implementation of X-ALD NBS in their states [69-71]. The Ministry of Health of the Netherlands added ALD in the NBS panel in 2015, but only for males [72]. A prospective pilot study was first implemented to assess feasibility and establish the algorithm that identifies only males. Broad implementation began on January 1, 2021.

Another NBS pilot project is currently underway in Taiwan for X-ALD. Started in 2016, it has already screened 45,796 newborns. Results have not yet been published (NCT02952482) [73].
The characteristics of NBS programs in X-ALD are reported in Table 4.

\subsection{Metachromatic leukodystrophy}

MLD is an autosomal recessively-inherited metabolic disease characterized by accumulation of sulfatides in the central and peripheral nervous system due to deficiency of the enzyme arylsulfatase A, which leads to demyelination. The main characteristics of the disease are a deterioration of motor or cognitive functions, depending on the subtype, leading to severe disability and death after a very variable evolution and duration of the disease.

Gene therapy has recently been approved in the US and the EU (OTL-200). Pre-symptomatic patients have presented much better outcome $[74,75]$.

To our knowledge, only one pilot project aimed at demonstrating the feasibility of MLD NBS took place in the USA in 2020, screening 27,335 de-identified DBS [76].

The characteristics of NBS program in MLD are reported in Table 4.

\section{Discussion}

We identified seven diseases with a clear peripheral neurologic system component that have been targeted by NBS over the last twenty years. SMA is certainly the disease for which NBS has the greatest consensus, given the importance of early intervention demonstrated or suggested in all clinical developments, and the dramatic efficacy of pre-symptomatic treatments [26,77]. Interestingly, SMA NBS programs were initiated before the approval of disease modifying treatments but have contributed to demonstrating the dramatic efficacy of early treatment. The low cost of screening [78] which contrasts with the very high societal cost of untreated disease, or post-symptomatic diseases [79] also suggests that the NBS program is highly cost-effective, even if this remains to be formally demonstrated. The treatment algorithm, including the difficult question of patients with symptoms at birth and on the other hand of the spectrum patients with four copies of $S M N 2$ remains to be established [80,81]. Although an agreement was revised in favour of early treatment of patients with four copies, there is no clear and unanimous attitude today towards the choice of the treatment of these patients.

NBS of Pompe disease brings different technical and prognostic consideration, the most significant of which is the proportion at birth of late onset forms, for which there is today no indication of early treatment, compared to the infantile form, for which a treatment certainly should be initiated. A recent study in Pennsylvania has illustrated that the earlier form is less prevalent than later forms with a ratio of 1:15 [38]; this situation is completely different to that of SMA in which the more severe form represents about $60 \%$ of all forms [82]. As it is the case for other the other neuromuscular diseases with metabolic origin (i.e., Krabbe, 
Table 4

Newborn screening programs in Krabbe disease, X-ALD and MLD.

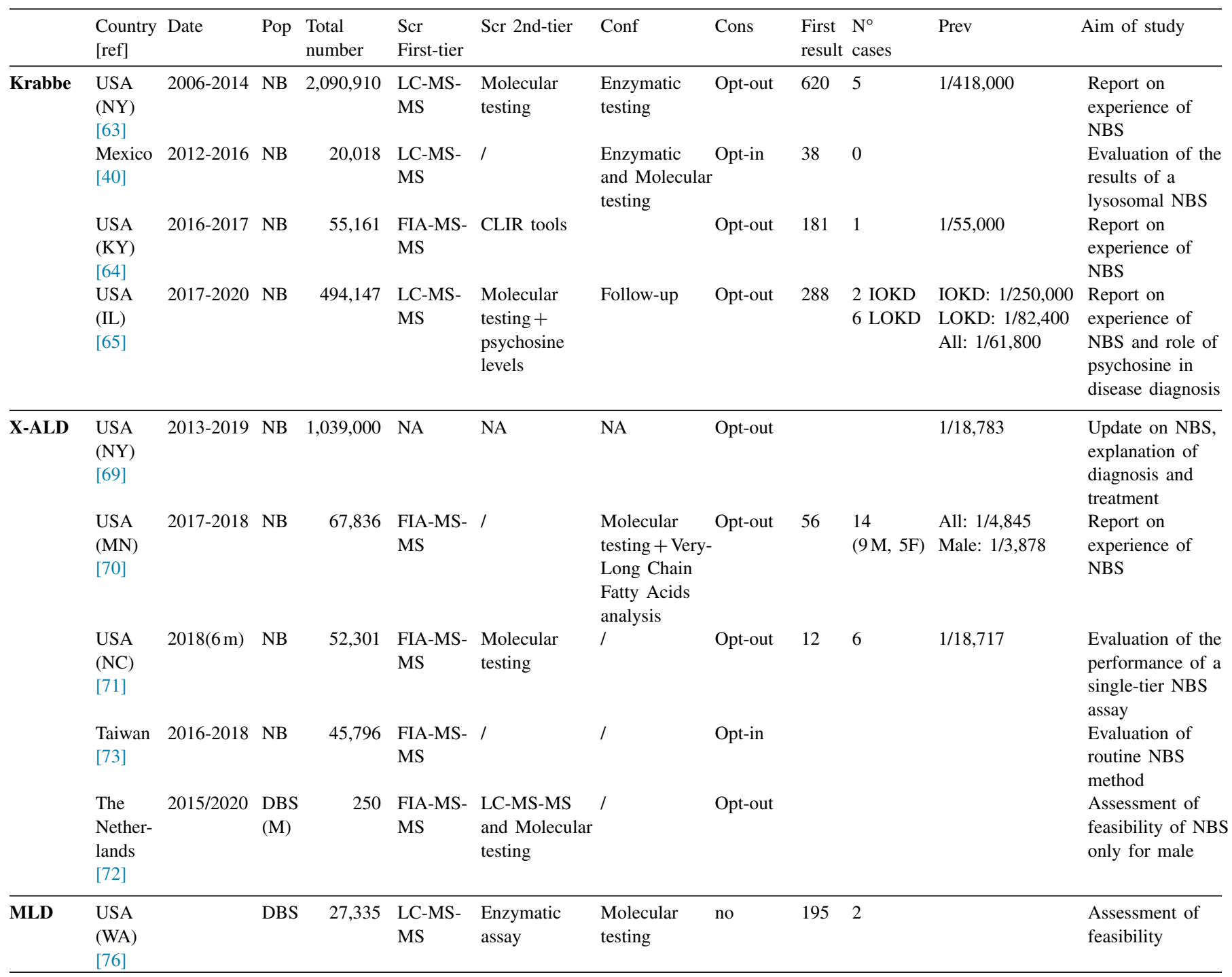

List of abbreviations: Conf: Confirmatory assay; Cons: parents' method of consent; DBS: DBS deidentified; FIA-MS-MS: flow-injection mass spectrometry; F: Female; First result: Positive first result or inconclusive; IL: Illinois; IOKD: infantile onset Krabbe disease; KY: Kentucky; LC-MS-MS: liquid-chromatography mass spectrometry; LOKD: late onset Krabbe disease; M: Male; m: months; NA: not available; MN: Minnesota; NB: Newborn; NY: New York state; NC: North Carolina; $\mathrm{N}^{\circ}$ cases: Number of confirmed cases; Pop: description of population screened; Prev: Prevalence; Ref: references used; Scr: Screening assay; WA: Washington.

X-ALD and MLD), the setup of specific and laborious assays tends to hamper the implementation of corresponding NBS programs.

Aside from deflazacort, which is usually not prescribed before the age of three years, all approved treatments for DMD are mutation-specific, which raises questions as to the utility of broadly screening for CK or CK-MM levels at birth. Indeed, only about $30 \%$ of patients could potentially benefit from early detection, however this remains hypothetical as it has not yet been demonstrated. Recently, an assay has been proposed for identifying only the patients with a mutation eligible for exon [83]. The lack of specificity of CK level also makes the use of this test difficult to use at a population level.
As discussed in the present review, some neuromuscular diseases are currently amenable to NBS as they are identifiable either by a sensitive biochemical assay or by a specific hotspot mutation (e.g., deletion of SMN1 exon 7 in SMA). However, most NMDs have neither a specific biomarker nor a prevalent molecular defect. Screening for these disorders is therefore not suitable for current technological NBS platforms, which are biochemically driven. Two clear examples can be found in CMS and BVVL. To date, 34 genes are described as being involved in CMS [84]. Low-cost treatments such as salbutamol or pyridostigmine can avoid sudden death or disability in the course of a long diagnostic journey. BVVL, a recessive disorder caused by a loss of function mutation in one of 
the three different intestinal riboflavin transporter genes, can be managed with a high dose of riboflavin [85], and leads to severe bulbospinal atrophy in absence of treatment. Unfortunately, neither CMS not BVVL can be identified by any sensitive biomarker and are thus not amenable to NBS; identification of such disorders at birth should therefore be carried out through whole exome or targeted sequencing.

The same will apply for conditions for which transformative clinical or pre-clinical results have been reported recently. One example is X-linked myotubular myopathy, a rare congenital myopathy caused by a loss of function mutation in the $\mathrm{X}$ chromosome located myotubularin protein, which leads to early death in the most severe form and to severe disability in the milder forms [86,87]. Xlinked myotubular myopathy patients treated with gene therapy have initially demonstrated dramatic improvement [88] and although severe safety concerns have been raised [89], it is very likely that a drug will be approved for the condition, as several other therapeutic approaches are in development [90].

Taken as a whole, we should expect the future for NBS for neuromuscular disorders globally to pass through a technological paradigm shift, from a biochemical to a geneticbased approach. The rapid development of therapies also requires the prospect of promptly adapting the list of treated conditions in order to allow innovative therapies to achieve utmost efficacy.

NBS and carrier screening (explored in another review of this issue), should be simultaneously implemented. Carrier screening has the potential to decrease the incidence of diseases in a population, but fails to address the whole population, and is obviously socially oriented. It fails to identify neo-mutations, a situation in which both variants are on the same allele (which is not rare in SMA) and of course cannot fully cover babies with an unknown father or with one or both parents absent. NBS is universal, addresses all children regardless of parents' conditions, and allows both patient and society to obtain the maximal benefit of innovative medications.

Let's hope that in 45 years, our 135-year-old dear myologist, wherever his rambling of child neurologist has led him, could list 90 diseases that we have happily blown out as we wish him to happily blow out his 90 candles today.

\section{Funding}

This research did not receive any specific grant from funding agencies in the public, commercial, or not-for-profit sectors.

\section{Declaration of Competing Interest}

The authors declare that they have no known competing financial interests or personal relationships that could have appeared to influence the work reported in this paper.

\section{Acknowledgements}

The authors thank Dominic Tromans for language editing.

\section{Supplementary materials}

Supplementary material associated with this article can be found, in the online version, at doi:10.1016/j.nmd.2021.07. 008 .

\section{References}

[1] Dubowitz V. Screening for Duchenne muscular dystrophy. Arch Dis Child 1976;51:249-51. doi:10.1136/adc.51.4.249.

[2] Dubowitz V. Familial low birthweight dwarfism with an unusual facies and a skin eruption. J Med Genet 1965;2:12-17. doi:10.1136/jmg.2.1.12.

[3] Ciafaloni E, Fox DJ, Pandya S, Westfield CP, Puzhankara S, Romitti PA, et al. Delayed diagnosis in duchenne muscular dystrophy: data from the Muscular Dystrophy Surveillance, Tracking, and Research Network (MD STARnet). J Pediatr 2009;155:380-5. doi:10.1016/j.jpeds.2009.02. 007.

[4] Lin CW, Kalb SJ, Yeh WS. Delay in diagnosis of spinal muscular atrophy: a systematic literature review. Pediatr Neurol 2015;53:293-300. doi:10.1016/j.pediatrneurol.2015.06.002.

[5] Kishnani PS, Amartino HM, Lindberg C, Miller TM, Wilson A, Keutzer J. Timing of diagnosis of patients with Pompe disease: data from the Pompe registry. Am J Med Genet A 2013;161A:2431-43 https://doi.org/10.1002/ajmg.a.36110.

[6] van Geel BM, Assies J, Haverkort EB, Barth PG, Wanders RJ, Schutgens RB, et al. Delay in diagnosis of X-linked adrenoleukodystrophy. Clin Neurol Neurosurg 1993;95:115-20. doi:10.1016/0303-8467(93)90004-z.

[7] Dangouloff T, Servais L. Clinical evidence supporting early treatment of patients with spinal muscular atrophy: current perspectives. Ther Clin Risk Manag 2019;15:1153-61. doi:10.2147/TCRM.S172291.

[8] Yang C-F, Yang CC, Liao H-C, Huang L-Y, Chiang C-C, Ho H-C, et al. Very early treatment for infantile-onset pompe disease contributes to better outcomes. J Pediatr 2016;169 174-80.e1. https://doi.org/10.1016/j.jpeds.2015.10.078.

[9] Delstanche S, Servais L, Gidaro T. Improved muscular weakness during asthma exacerbation. JAMA Neurol 2017;74:353-4. doi:10.1001/ jamaneurol.2016.4069.

[10] Wilson J, Jungner G. Principles and practice of screening. Geneva: WHO; 1968.

[11] Loeber JG, Platis D, Zetterström RH, Almashanu S, Boemer F, Bonham JR, et al. Neonatal screening in europe revisited: an ISNS perspective on the current state and developments since 2010. Int $\mathbf{J}$ Neonatal Screen 2021;7. doi:10.3390/ijns7010015.

[12] Moher D, Liberati A, Tetzlaff J, Altman DG. Preferred reporting items for systematic reviews and meta-analyses: the PRISMA statement. PLoS Med 2009;6:e1000097. doi:10.1371/journal.pmed.1000097.

[13] Ramdas S, Servais L. New treatments in spinal muscular atrophy: an overview of currently available data. Expert Opin Pharmacother 2020;21:307-15. doi:10.1080/14656566.2019.1704732.

[14] Finkel RS, Chiriboga CA, Vajsar J, Day JW, Montes J, De Vivo DC, et al. Treatment of infantile-onset spinal muscular atrophy with nusinersen: a phase 2, open-label, dose-escalation study. Lancet 2016;388:3017-26. doi:10.1016/s0140-6736(16)31408-8.

[15] Day JW, Finkel RS, Chiriboga CA, Connolly AM, Crawford TO, Darras BT, et al. Onasemnogene abeparvovec gene therapy for symptomatic infantile-onset spinal muscular atrophy in patients with two copies of SMN2 (STR1VE): an open-label, single-arm, multicentre, phase 3 trial. Lancet Neurol 2021;20:284-93. doi:10.1016/ S1474-4422(21)00001-6. 
[16] Baranello G, Darras B, Day J, Deconinck N, Klein A, Masson R, et al. Risdiplam in Type 1 spinal muscular atrophy. N Engl J Med 2021;384(10):915-23 https://doi.org/10.1056/NEJMoa2009965.

[17] Servais L, Baranello G, Scoto M, Daron A, Oskoui M. Therapeutic interventions for spinal muscular atrophy: preclinical and early clinical development opportunities. Expert Opin Investig Drugs 2021;30:519-27. doi:10.1080/13543784.2021.1904889.

[18] Chien YH, Chiang SC, Weng WC, Lee NC, Lin CJ, Hsieh WS, et al. Presymptomatic diagnosis of spinal muscular atrophy through newborn screening. J Pediatr 2017;190 124-9.e1. https://doi.org/10.1016/j.jpeds.2017.06.042.

[19] Kraszewski JN, Kay DM, Stevens CF, Koval C, Haser B, Ortiz V, et al. Pilot study of population-based newborn screening for spinal muscular atrophy in New York state. Genet Med 2018;20:608-13 https://doi.org/10.1038/gim.2017.152.

[20] Kucera KS, Taylor JL, Robles VR, Clinard K, Migliore B, Boyea BL, et al. A voluntary statewide newborn screening pilot for spinal muscular atrophy: results from early check. Int J Neonatal Screen 2021;7(1):20 https://doi.org/https://dx.doi.org/10.3390/ijns7010020.

[21] Vill K, Schwartz O, Blaschek A, Glaser D, Nennstiel U, Wirth B, et al. Newborn screening for spinal muscular atrophy in Germany: clinical results after 2 years. Orphanet J Rare Dis 2021;16(1):153 https://doi.org/https://dx.doi.org/10.1186/s13023-021-01783-8.

[22] Boemer F, Caberg JH, Dideberg V, Dardenne D, Bours V, Hiligsmann M, et al. Newborn screening for SMA in Southern Belgium. Neuromuscul Disord 2019;29:343-9. doi:10.1016/j.nmd.2019.02.003.

[23] Kariyawasam DST, Russell JS, Wiley V, Alexander IE, Farrar MA. The implementation of newborn screening for spinal muscular atrophy: the Australian experience. Genet Med 2019;22:557-65 https://doi.org/10.1038/s41436-019-0673-0.

[24] McMillan HJ, Kernohan KD, Yeh E, Amburgey K, Boyd J, Campbell C, et al. Newborn screening for spinal muscular atrophy: Ontario testing and follow-up recommendations. Can J Neurol Sci 2020:1-8. doi:10. 1017/cjn.2020.229.

[25] Shinohara M, Niba ETE, Wijaya YOS, Takayama I, Mitsuishi C, Kumasaka S, et al. A novel system for spinal muscular atrophy screening in newborns: Japanese pilot study. Int J Neonatal Screen 2019;5:41. doi:10.3390/ijns5040041.

[26] De Vivo DC, Bertini E, Swoboda KJ, Hwu WL, Crawford TO, Finkel RS, et al. Nusinersen initiated in infants during the presymptomatic stage of spinal muscular atrophy: interim efficacy and safety results from the Phase 2 NURTURE study. Neuromuscul Disord 2019;29:842-56. doi:10.1016/j.nmd.2019.09.007.

[27] Dangouloff T, Vrščaj E, Servais L, Osredkar D. Newborn screening programs for spinal muscular atrophy worldwide: where we stand and where to go. Neuromuscul Disord 2021;31:574-82. doi:10.1016/j.nmd. 2021.03.007.

[28] Kay DM, Stevens CF, Parker A, Saavedra-Matiz CA, Sack V, Chung WK, et al. Implementation of population-based newborn screening reveals low incidence of spinal muscular atrophy. Genet Med 2020;22:1296-302. doi:10.1038/s41436-020-0824-3.

[29] Dangouloff T, Boemer F, Caberg JH, Servais L. Correspondence on: "Discrepancy in Spinal Muscular Atrophy Incidence findings in newborn screening programs: the influence of carrier screening?" by Kay et al. Genet Med 2020;22:1913-14. doi:10.1038/s41436-020-0887-1.

[30] Li C, Desai AK, Gupta P, Dempsey K, Bhambhani V, Hopkin RJ, et al. Transforming the clinical outcome in CRIM-negative infantile Pompe disease identified via newborn screening: the benefits of early treatment with enzyme replacement therapy and immune tolerance induction. Genet Med 2021;23:845-55. doi:10.1038/s41436-020-01080-y.

[31] Lai C-J, Hsu T-R, Yang C-F, Chen S-J, Chuang Y-C, Niu D-M. Cognitive development in infantile-onset pompe disease under very early enzyme replacement therapy. J Child Neurol 2016;31:1617-21. doi:10.1177/0883073816665549.

[32] Chien Y-H, Chiang S-C, Zhang XK, Keutzer J, Lee N-C, Huang A-C, et al. Early detection of Pompe disease by newborn screening is feasible: results from the Taiwan screening program. Pediatrics 2008;122:e39-45 https://doi.org/https://dx.doi.org/10.1542/peds.2007-2222.
[33] Labrousse P, Chien Y-H, Pomponio RJ, Keutzer J, Lee N-C, Akmaev VR, et al. Genetic heterozygosity and pseudodeficiency in the Pompe disease newborn screening pilot program. Mol Genet Metab 2010;99:379-83 https://doi.org/https://dx.doi.org/10.1016/j.ymgme.2009.12.014.

[34] Chiang S-C, Hwu W-L, Lee N-C, Hsu L-W, Chien Y-H. Algorithm for Pompe disease newborn screening: results from the Taiwan screening program. Mol Genet Metab 2012;106:281-6. doi:10.1016/j.ymgme. 2012.04.013.

[35] Yang C-F, Liu H-C, Hsu T-R, Tsai F-C, Chiang S-F, Chiang $\mathrm{C}-\mathrm{C}$, et al. A large-scale nationwide newborn screening program for Pompe disease in Taiwan: towards effective diagnosis and treatment. Am J Med Genet A 2014;164A:54-61 https://doi.org/https://dx.doi.org/10.1002/ajmg.a.36197.

[36] Klug TL, Swartz LB, Washburn J, Brannen C, Kiesling JL. Lessons learned from Pompe disease newborn screening and follow-up. Int J Neonatal Screen 2020;6(1):11 https://doi.org/https://dx.doi.org/10.3390/ijns6010011.

[37] Burton BK, Charrow J, Hoganson GE, Fleischer J, Grange DK, Braddock SR, et al. Newborn screening for Pompe disease in Illinois: experience with 684,290 infants. Int J Neonatal Screen 2020;6:8-12 https://doi.org/https://dx.doi.org/10.3390/ijns6010004.

[38] Ficicioglu C, Ahrens-Nicklas RC, Barch J, Cuddapah SR, DiBoscio BS, DiPerna JC, et al. Newborn screening for Pompe disease: Pennsylvania experience. Int J Neonatal Screen 2020;6:89 https://doi.org/https://dx.doi.org/10.3390/ijns6040089.

[39] Tang H, Feuchtbaum L, Sciortino S, Matteson J, Mathur D, Bishop $\mathrm{T}$, et al. The first year experience of newborn screening for Pompe disease in California. Int J Neonatal Screen 2020;6(1):9 https://doi.org/https://dx.doi.org/10.3390/ijns6010009.

[40] Navarrete-Martinez JI, Limon-Rojas AE, Gaytan-Garcia M de J, Reyna-Figueroa J, Wakida-Kusunoki G, Delgado-Calvillo MDR, et al. Newborn screening for six lysosomal storage disorders in a cohort of Mexican patients: three-year findings from a screening program in a closed Mexican health system. Mol Genet Metab 2017;121:16-21 https://doi.org/https://dx.doi.org/10.1016/j.ymgme.2017.03.001.

[41] Momosaki K, Kido J, Yoshida S, Sugawara K, Miyamoto T, Inoue $\mathrm{T}$, et al. Newborn screening for Pompe disease in Japan: report and literature review of mutations in the GAA gene in Japanese and Asian patients. J Hum Genet 2019;64:741-55. doi:10. 1038/s10038-019-0603-7.

[42] Bravo H, Neto EC, Schulte J, Pereira J, Filho CS, Bittencourt F, et al. Investigation of newborns with abnormal results in a newborn screening program for four lysosomal storage diseases in Brazil. Mol Genet Metab Reports 2017;12:92-7 https://doi.org/https://dx.doi.org/10.1016/j.ymgmr.2017.06.006.

[43] Dooley J, Gordon KE, Dodds L, MacSween J. Duchenne muscular dystrophy: a 30-year population-based incidence study. Clin Pediatr (Phila) 2010;49:177-9. doi:10.1177/0009922809347777.

[44] Shimizu-Motohashi Y, Komaki H, Motohashi N, Takeda S, Yokota T, Aoki Y. Restoring dystrophin expression in Duchenne muscular dystrophy: current status of therapeutic approaches. J Pers Med 2019;9(1). doi:10.3390/jpm9010001.

[45] Ke Q, Zhao Z-Y, Griggs R, Wiley V, Connolly A, Kwon J, et al. Newborn screening for Duchenne muscular dystrophy in China: follow-up diagnosis and subsequent treatment. World J Pediatr 2017;13:197-201 https://doi.org/https://dx.doi.org/10.1007/s12519-017-0036-3.

[46] Mendell JR, Shilling C, Leslie ND, Flanigan KM, Dahhak R, GastierFoster J, et al. Evidence-based path to newborn screening for Duchenne muscular dystrophy. Ann Neurol 2012;71:304-13. doi:10.1002/ana. 23528.

[47] Drousiotou A, Ioannou P, Georgiou T, Mavrikiou E, Christopoulos G, Kyriakides $\mathrm{T}$, et al. Neonatal screening for Duchenne muscular dystrophy: a novel semiquantitative application of the bioluminescence test for creatine kinase in a pilot national program in Cyprus. Genet Test 1998;2:55-60. doi:10.1089/gte.1998.2.55. 
[48] Moat SJ, Bradley DM, Salmon R, Clarke A, Hartley L. Newborn bloodspot screening for Duchenne muscular dystrophy: 21 years experience in Wales (UK). Eur J Hum Genet 2013;21:1049-53 https://doi.org/https://dx.doi.org/10.1038/ejhg.2012.301.

[49] Chung J, Smith AL, Hughes SC, Niizawa G, Abdel-Hamid HZ, Naylor EW, et al. Twenty-year follow-up of newborn screening for patients with muscular dystrophy. Muscle Nerve 2016;53:570-8 https://doi.org/https://dx.doi.org/10.1002/mus.24880.

[50] Greenberg CR, Rohringer M, Jacobs HK, Averill N, Nylen E, van Ommen GJ, et al. Gene studies in newborn males with Duchenne muscular dystrophy detected by neonatal screening. Lancet 1988;2:4257. doi:10.1016/s0140-6736(88)90414-X.

[51] Ellis JA, Vroom E, Muntoni F. 195th ENMC International Workshop: newborn screening for Duchenne muscular dystrophy 14-16th December 2012, Naarden, The Netherlands. Neuromuscul Disord 2013;23:682-9. doi:10.1016/j.nmd.2013.05.008.

[52] Drummond LM. Creatine phosphokinase levels in the newborn and their use in screening for Duchenne muscular dystrophy. Arch Dis Child 1979;54:362-6. doi:10.1136/adc.54.5.362.

[53] Plauchu H, Dorche C, Cordier MP, Guibaud P, Robert JM. Duchenne muscular dystrophy: neonatal screening and prenatal diagnosis. Lancet 1989;1:669. doi:10.1016/s0140-6736(89)92170-3.

[54] Scheuerbrandt G, Lundin A, Lövgren T, Mortier W. Screening for Duchenne muscular dystrophy: an improved screening test for creatine kinase and its application in an infant screening program. Muscle Nerve 1986;9:11-23. doi:10.1002/mus.880090103.

[55] Theadom A, Rodrigues M, Roxburgh R, Balalla S, Higgins C, Bhattacharjee R, et al. Prevalence of muscular dystrophies: a systematic literature review. Neuroepidemiology 2014;43:259-68. doi:10.1159/ 000369343.

[56] Pascual-Gilabert M, López-Castel A, Artero R. Myotonic dystrophy type 1 drug development: a pipeline toward the market. Drug Discov Today 2021. doi:10.1016/j.drudis.2021.03.024.

[57] Johnson NE, Butterfield RJ, Mayne K, Newcomb T, Imburgia C, Dunn D, et al. Population-based prevalence of Myotonic dystrophy Type 1 using genetic analysis of statewide blood screening program. Neurology 2021;96:e1045-53 https://doi.org/https://dx.doi.org/10.1212/WNL.0000000000011425.

[58] Orsini JJ, Escolar ML, Wasserstein MP, Caggana M. Krabbe disease. GeneReviews ${ }^{\circledR}$ [Internet]. Adam MP, Ardinger HH, Pagon RA, Wallace SE, Bean LJH, Stephens K, editors et al., editors, Washington, Seattle: Seattle Univ; 1993. 1993-2020. 2000 Jun 19 [updated 2018 Oct 11]., Seattle (WA).

[59] Wenger DA, Rafi MA, Luzi P, Datto J, Costantino-Ceccarini E. Krabbe disease: genetic aspects and progress toward therapy. Mol Genet Metab 2000;70:1-9. doi:10.1006/mgme.2000.2990.

[60] Graf WD. Stem cell transplantation in Krabbe disease: new truths discovered and opinions change. Neurology 2017;89:1318-19. doi:10. 1212/WNL.0000000000004427.

[61] Duffner PK, Caviness VSJ, Erbe RW, Patterson MC, Schultz KR, Wenger DA, et al. The long-term outcomes of presymptomatic infants transplanted for Krabbe disease: report of the workshop held on July 11 and 12, 2008, Holiday Valley, New York. Genet Med 2009;11:450-4. doi:10.1097/GIM.0b013e3181a16e04.

[62] Wasserstein MP, Andriola M, Arnold G, Aron A, Duffner P, Erbe RW, et al. Clinical outcomes of children with abnormal newborn screening results for Krabbe disease in New York State. Genet Med 2016;18:123543. doi:10.1038/gim.2016.35.

[63] Orsini JJ, Kay DM, Saavedra-Matiz CA, Wenger DA, Duffner PK, Erbe RW, et al. Newborn screening for Krabbe disease in New York State: the first eight years' experience. Genet Med 2016;18:239-48. doi:10.1038/gim.2015.211.

[64] Minter Baerg MM, Stoway SD, Hart J, Mott L, Peck DS, Nett SL, et al. Precision newborn screening for lysosomal disorders. Genet Med 2018;20:847-54 https://doi.org/https://dx.doi.org/10.1038/gim.2017.194.

[65] Basheeruddin K, Shao R, Balster F, Gardley P, Ashbaugh L. Newborn screening for Krabbe disease-Illinois experience: role of psychosine in diagnosis of the disease. Int J Neonatal Screen 2021;7. doi:10.3390/ ijns 7020024 .

[66] Ehmann P, Lantos JD. Ethical issues with testing and treatment for Krabbe disease. Dev Med Child Neurol 2019;61:1358-61. doi:10.1111/ dmcn.14258.

[67] Mallack EJ, Turk B, Yan H, Eichler FS. The landscape of hematopoietic stem cell transplant and gene therapy for X-linked adrenoleukodystrophy. Curr Treat Options Neurol 2019;21:61. doi:10. 1007/s11940-019-0605-y.

[68] Health Resources and Services Administration (HRSA). Baby's first test 2020. https://www.babysfirsttest.org.

[69] Eng L, Regelmann MO. Adrenoleukodystrophy in the era of newborn screening. Curr Opin Endocrinol Diabetes Obes 2020;27:47-55. doi:10. 1097/MED.0000000000000515.

[70] Wiens K, Berry SA, Choi H, Gaviglio A, Gupta A, Hietala A, et al. A report on state-wide implementation of newborn screening for $\mathrm{X}$ linked Adrenoleukodystrophy. Am J Med Genet A 2019;179:1205-13. doi:10.1002/ajmg.a.61171.

[71] Lee S, Clinard K, Young SP, Rehder CW, Fan Z, Calikoglu AS, et al. Evaluation of X-linked adrenoleukodystrophy newborn screening in North Carolina. JAMA Netw Open 2020;3:e1920356. doi:10.1001/ jamanetworkopen.2019.20356.

[72] Barendsen RW, Dijkstra IME, Visser WF, Alders M, Bliek J, Boelen A, et al. Adrenoleukodystrophy newborn screening in the Netherlands (SCAN Study): the X-factor. Front Cell Dev Biol 2020;8:499. doi:10. 3389/fcell.2020.00499.

[73] National Librairy of Medicine N. Clinical trial 2021. https://clinicaltrials.gov/ct2/show/NCT02952482?term=NCT02952482 $\&$ draw $=2 \&$ rank $=1$.

[74] Rosenberg JB, Kaminsky SM, Aubourg P, Crystal RG, Sondhi D. Gene therapy for metachromatic leukodystrophy. J Neurosci Res 2016;94:1169-79. doi:10.1002/jnr.23792.

[75] Biffi A, Montini E, Lorioli L, Cesani M, Fumagalli F, Plati T, et al. Lentiviral hematopoietic stem cell gene therapy benefits metachromatic leukodystrophy. Science 2013;341:1233158. doi:10. 1126/science. 1233158.

[76] Hong X, Daiker J, Sadilek M, Ruiz-Schultz N, Kumar AB, Norcross S, et al. Toward newborn screening of metachromatic leukodystrophy: results from analysis of over 27,000 newborn dried blood spots. Genet Med 2021;23:555-61. doi:10.1038/s41436-020-01017-5.

[77] Strauss KA, Swoboda KJ, Farrar M, McMillan HJ, Parsons J, Krueger J, et al. AVXS-101 gene-replacement therapy in presymptomatic spinal muscular atrophy: SPR1NT study update. Am Acad Neurol 20192019 - 71st Annu Meet.

[78] Dangouloff T, Burghes A, Tizzano EF, Servais L, Bertini E, Boemer F, et al. 244th ENMC international workshop: newborn screening in spinal muscular atrophy May 10-12, 2019, Hoofdorp, The Netherlands. Neuromuscul. Disord. 2020;30:93-103 Elsevier Ltd. doi:10.1016/j.nmd. 2019.11.002.

[79] Dangouloff T, Botty C, Beaudart C, Servais L, Hiligsmann M. Systematic literature review of the economic burden of spinal muscular atrophy and economic evaluations of treatments. Orphanet J Rare Dis 2021;16:47. doi:10.1186/s13023-021-01695-7.

[80] Glascock J, Sampson J, Haidet-Phillips A, Connolly A, Darras B, Day J, et al. Treatment algorithm for infants diagnosed with spinal muscular atrophy through newborn screening. J Neuromuscul Dis 2018;5:145-58. doi: $10.3233 /$ jnd-180304.

[81] Glascock J, Sampson J, Connolly AM, Darras BT, Day JW, Finkel R, et al. Revised recommendations for the treatment of infants diagnosed with spinal muscular atrophy via newborn screening who have 4 copies of SMN2. J Neuromuscul Dis 2020;7:97-100. doi:10.3233/ JND- 190468.

[82] Verhaart IEC, Robertson A, Wilson IJ, Aartsma-Rus A, Cameron S, Jones CC, et al. Prevalence, incidence and carrier frequency of 5qlinked spinal muscular atrophy - a literature review. Orphanet J Rare Dis 2017;12:124. doi:10.1186/s13023-017-0671-8. 
[83] Beckers P, Caberg J-H, Dideberg V, Dangouloff T, den Dunnen JT, Bours V, et al. Newborn screening of duchenne muscular dystrophy specifically targeting deletions amenable to exon-skipping therapy. Sci Rep 2021;11. doi:10.1038/s41598-021-82725-z.

[84] Rodríguez Cruz PM, Cossins J, Beeson D, Vincent A. The neuromuscular junction in health and disease: molecular mechanisms governing synaptic formation and homeostasis. Front Mol Neurosci 2020;13:226. doi:10.3389/fnmol.2020.610964.

[85] Carreau C, Benoit C, Ahle G, Cauquil C, Roubertie A, Lenglet T, et al. Late-onset riboflavin transporter deficiency: a treatable mimic of various motor neuropathy aetiologies. J Neurol Neurosurg Psychiatry 2020. doi:10.1136/jnnp-2020-323304.

[86] Annoussamy M, Lilien C, Gidaro T, Gargaun E, Chê V, Schara U, et al. X-linked myotubular myopathy: a prospective international natural history study. Neurology 2019;92:e1852-67 https://doi.org/10.1212/WNL.0000000000007319.
[87] Amburgey K, Tsuchiya E, de Chastonay S, Glueck M, Alverez R, Nguyen C-T, et al. A natural history study of X-linked myotubular myopathy. Neurology 2017;89:1355-64 https://doi.org/10.1212/WNL.0000000000004415.

[88] Duong T, Harding G, Mannix S, Abel C, Phillips D, Alfano LN, et al. Use of the children's hospital of Philadelphia infant test of neuromuscular disorders (CHOP INTEND) in X-linked myotubular myopathy: content validity and psychometric performance. J Neuromuscul Dis 2021;8:63-77. doi:10.3233/JND-200479.

[89] Shieh PB, Bönnemann CG, Müller-Felber W, Blaschek A, Dowling JJ, Kuntz NL, et al. Re: "moving forward after two deaths in a gene therapy trial of myotubular myopathy" by Wilson and Flotte. Hum Gene Ther 2020;31:787. doi:10.1089/hum.2020.217.

[90] Tasfaout H, Cowling BS, Laporte J. Centronuclear myopathies under attack: a plethora of therapeutic targets. J Neuromuscul Dis 2018;5:387406. doi:10.3233/JND- 180309. 